\title{
Interactive 3D Visualization of Mathematical Functions Using VRML
}

Qiming Wang

Bonita Saunders U.S. DEPARTMENT OF COMMERCE Technology Administration Information Technology Laboratory National Institute of Standards and Technology

Gaithersburg, MD 20899

QC

100

.056

HO. 6289

1999 



\title{
Interactive 3D Visualization of Mathematical Functions Using VRML
}

\author{
Qiming Wang \\ Bonita Saunders \\ U.S. DEPARTMENT OF COMMERCE \\ Technology Administration \\ Information Technology Laboratory \\ National Institute of Standards \\ and Technology \\ Gaithersburg, MD 20899
}

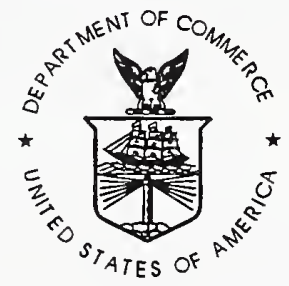

U.S. DEPARTMENT OF COMMERCE William M. Daley, Secretary

TECHNOLOGY ADMINISTRATION Gary R. Bachula, Acting Under Secretary for Technology

NATIONAL INSTITUTE OF STANDARDS

AND TECHNOLOGY

Raymond G. Kammer, Director 



\title{
Interactive 3D Visualization of Mathematical Functions Using VRML
}

\author{
Qiming Wang, Bonita Saunders \\ Information Technology Laboratory \\ National Institute of Standards and Technology
}

\begin{abstract}
Although there have been no major revisions of the National Bureau of Standards Handbook of Mathematical Functions [1] since its first publication in 1964, it continues to be widely used by the mathematical and scientific community. As a result, NIST is engaged in a large scale project to update and expand the handbook and disseminate it in digital format on the World Wide Web. This electronic handbook is being called the Digital Library of Mathematical Functions (DLMF). A key feature of the DLMF will be dynamic $3 \mathrm{D}$ visualizations of special functions. This paper discusses some of the visualization results obtained to date using VRML, the Virtual Reality Modeling Language, a standard file format for describing the behavior and geometry of a $3 \mathrm{D}$ virtual world.
\end{abstract}

Keywords: VRML, Virtual Reality Modeling Language, visualization, 3D graphics, clipping, special functions

\section{Introduction}

One of the most well known publications to come out of the National Bureau of Standards, the predecessor organization of the National Institute of Standards and Technology (NIST), is the Handbook of Mathematical Functions [1], published in 1964. Unchanged since the tenth printing in 1972, it continues to be widely sold by the US Government Printing Office, Dover, and many other commercial publishers. The Science Citation Index indicates that the handbook was cited over 26,000 times during the period 1974-1997 in more than 1000 journals, and the number of citations continues to increase with time.

The continued interest in the handbook plus such factors as

- the clear advantages of electronic media for the construction and communication of ideas in technical fields;

- advances in basic mathematical and computational techniques associated with the classical special functions of the mathematical and physical sciences; and

- the identification of new functions having widespread importance in emerging applications 

have led NIST to embark on a massive project to update and expand the current handbook and disseminate it in digital format on the World Wide Web; see Lozier [2] for an early description and http://math.nist.gov/DigitalMathLib for current information on this new project. The new entity, which is being called the Digital Library of Mathematical Functions (DLMF), will make full use of advanced communications and computational resources. A key feature of the DLMF will be dynamic 3D visualizations of special functions that allow a user to conduct interactive explorations of the relationship between a function's mathematical or numerical properties and its graphical representations. The Virtual Reality Modeling Language (VRML) is a standard 3D file format for describing the behavior and geometry of a $3 \mathrm{D}$ virtual world, or scene. Its accessibility on the Internet and interactive capabilities make it an ideal candidate for this development work. This paper describes techniques we are using to generate VRML files that not only display 3D graphs, but also allow the user to gain a deeper understanding of the function by manipulating cutting planes perpendicular to the major axes in order to examine the 2D projection of the function at various locations.

\section{$3 \mathrm{D}$ visualization of special functions}

Like the original handbook, the DLMF is designed primarily for the use of scientists. A secondary, but important goal is to reach a much broader audience by making aspects of the DLMF accessible to educators and students. An obvious way to support these dual goals is to create $3 \mathrm{D}$ visualizations that are both exciting and informative. Fortunately, the graphical representations of many special functions are so complex and interesting that by designing visualizations that illustrate the features of interest to scientists we automatically produce displays that grab the attention of less technically oriented viewers. In any case, the development of the display requires close coordination with an expert in the field of special functions. Currently, we are concentrating on visualizations for the chapter on Airy functions, written by Prof. Frank Olver, one of the authors of the original handbook. The Airy functions, Ai and $\mathrm{Bi}$, occur in quantum mechanics, in the study of wave diffraction, electromagnetism, and other areas of physics and engineering, and arise as solutions of the second order differential equation

$$
\frac{d^{2} w}{d z^{2}}=z w .
$$

To obtain reliable data for the visualizations we used a double precision Fortran routine for the calculation of Airy functions written by D.E.Amos [3]. We wrote a $\mathrm{C}$ program that accepted this input data and generated a VRML file as output. In many cases we found that the graphs had to be scaled very carefully in order to make interesting features visible. However, for some functions, the variation in values over the domain was so extreme that simply adjusting the scaling was not enough. A 3D clipping algorithm could potentially help with the scaling, but to date we have been unsuccessful in finding suitable routines in the literature or in available packages. We first tried resetting values above a certain height to the same constant as was done by Thompson [4], but that produced the misleading "table" effect shown in Figure 1. We also tried suppressing the plotting of points where the function value was greater than a specified constant, but that produced plots with jagged edges that were equally misleading. Finally, we decided to use information from a contour plot of the function to restrict the domain to points where the function values were less than or equal to a specified constant. The contour information was used to construct the boundary of the domain, and a boundary fitted mesh was then placed over the domain as shown in Figure 2. By computing the Airy function only at values on the mesh, we obtained a smoothly clipped surface plot as shown in Figure 3. 



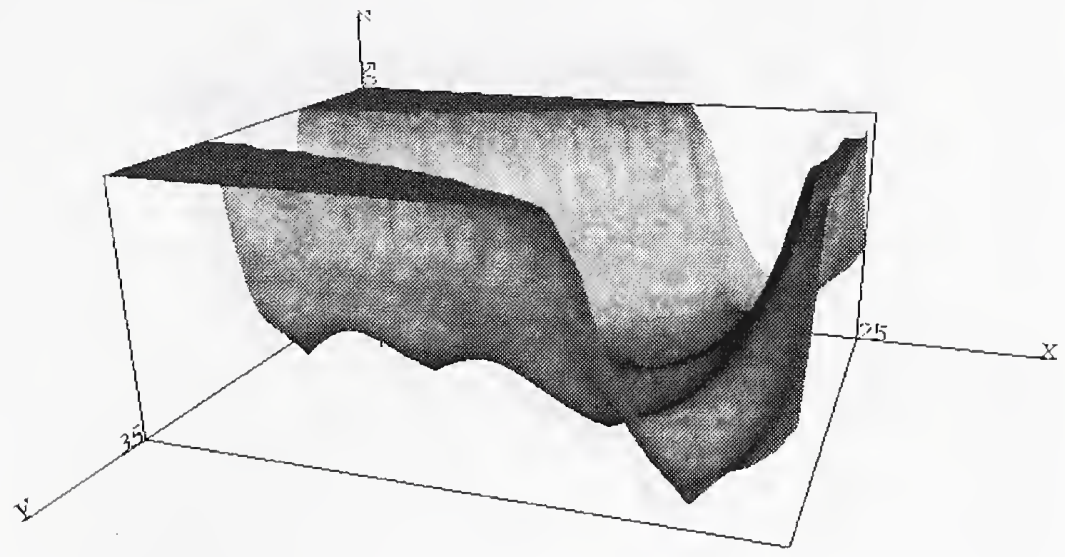

Figure 1: $\left|\mathrm{Bi}^{\prime}(z)\right|$, Modulus of the derivative of $\operatorname{Bi}(z)$.

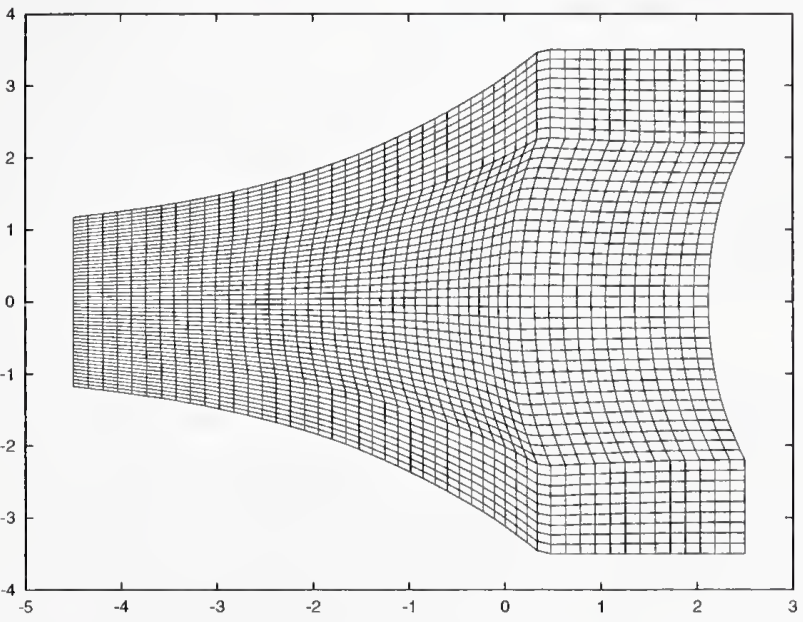

Figure 2: Contour mesh. 



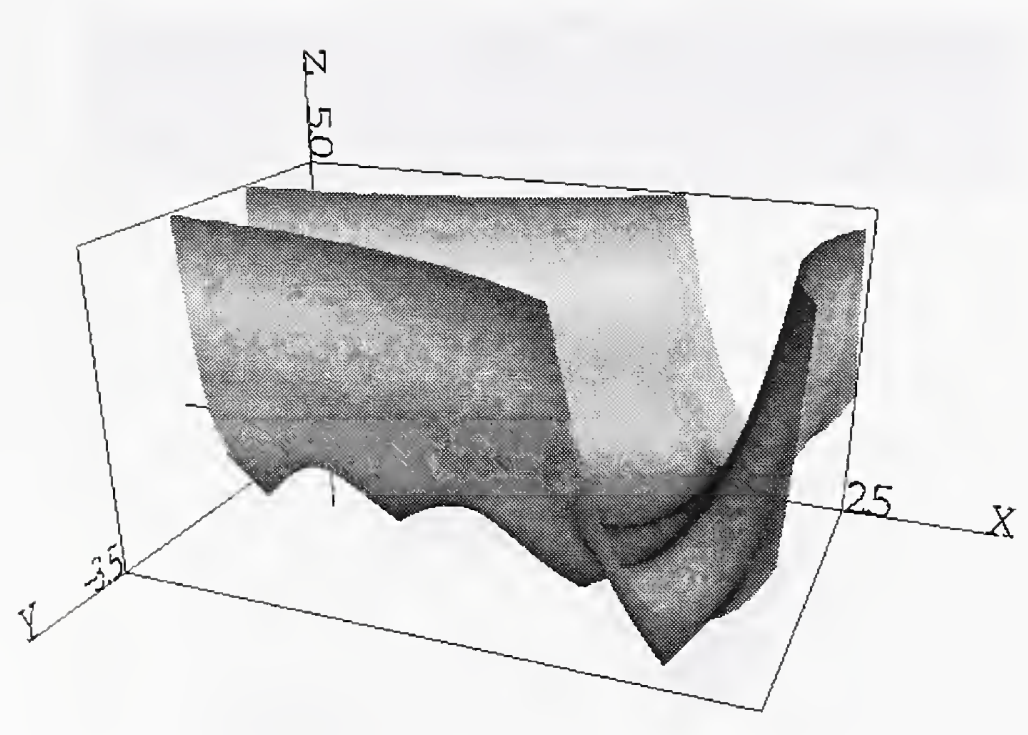

Figure 3: Clipped version of $\left|\mathrm{Bi}^{\prime}(z)\right|$.

\section{Intersection of $3 \mathrm{D}$ surfaces with cutting planes}

While a VRML browser gives the user the flexibility to examine a 3D display from an arbitrary direction, we also wanted to give the user a greater ability to interact with the visualization of the functions. DLMF project members noted that one very useful feature would be the ability to study the changes that occur in the intersection of a plane with a surface as the plane is moved through the surface. Using VRML we were able to create files that would generate cutting planes through a $3 \mathrm{D}$ surface. However, currently, the cutting planes are limited to planes perpendicular to the $\mathrm{X}$ and $\mathrm{Y}$ coordinate axes.

We defined a VRML PROTO called Cutplane to display the plane and compute the intersection of the plane with the surface data. In VRML a PROTO is a user defined reusable component. Cutplane searches the data to determine which surface points are closest to the specified plane and then performs a linear interpolation to obtain the coordinates for the intersection.

When the user opens the VRML display, the 3D-surface and a control panel appear. Figure 4 shows the look of the VRML display when the VRML browser CosmoPlayer is used. CosmoPlayer can be downloaded from http://cosmosoftware.com. We defined another VRML prototype, PROTO Dash to deal with the operation of the control panel. On the control panel, there are two lines of buttons. When the user clicks the $\mathrm{X}$ or $\mathrm{Y}$ button on the top line, the specified cutting plane will be shown. For example, clicking the $\mathrm{X}$ button causes a bounding box to appear around the figure and produces a cutting plane that will move perpendicular to the $\mathrm{X}$ axis. The buttons on the second row control the animation similar to those on a VCR: rewind, reverse, stop, play, and fast forward. When the user clicks the VCR buttons, the cutting plane moves in sync with the projected intersection curve, which is displayed on opposite faces of the bounding box. The text on the bottom of the browser shows the value of the cutting plane location. 



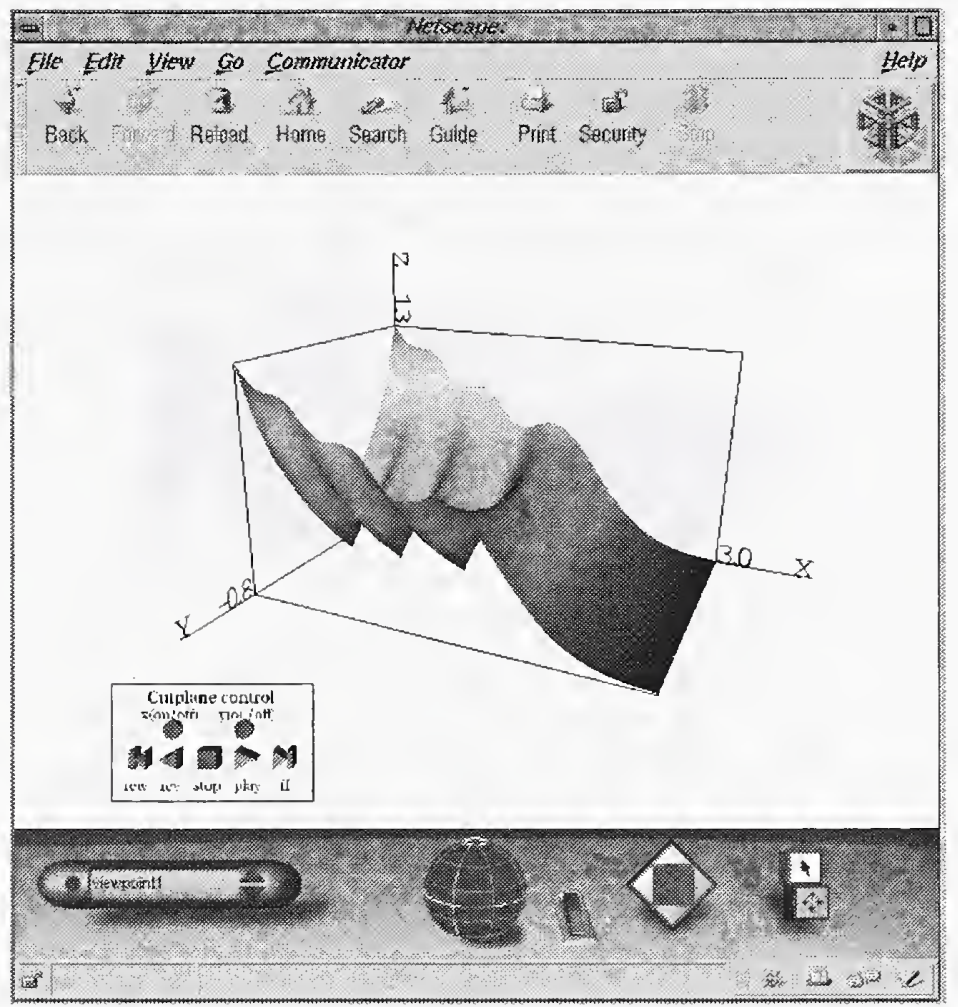

Figure 4: VRML display on CosmoPlayer.

Figure 5 shows the imaginary part of Airy function $\left|\mathrm{Ai}^{\prime}(z)\right|$ with a cutting plane in the Y direction. Figure 6 presents the real part of Airy function $\operatorname{Bi}(z)$ with a cutting plane in the $\mathrm{X}$ direction. These and other figures may be found at URL http://zing.ncsl.nist.gov/ wang/mathlib/new_ui/.

\section{Future research}

The initial attempt to develop interactive VRML visualizations for the DLMF has been very successful. Other DLMF project members are pleased about the results to date and have agreed to work closely with us in determining how and where visualization can best be used in the DLMF. We are already developing more efficient contour plotting code to facilitate the expansion of the cutting planes to the $\mathrm{Z}$ direction. Also, we are experimenting with the use of a slider bar to give the user more control over the location of the cutting plane. Another area where more research is needed is in the development of efficient clipping routines. This will especially be a problem when we begin looking at visualizations of functions like the Gamma function where the domain of computation will contain holes. Each chapter will produce new challenges, but the hope is that much of what we are learning now can be easily applied to creating suitable visualizations for the other chapters. 



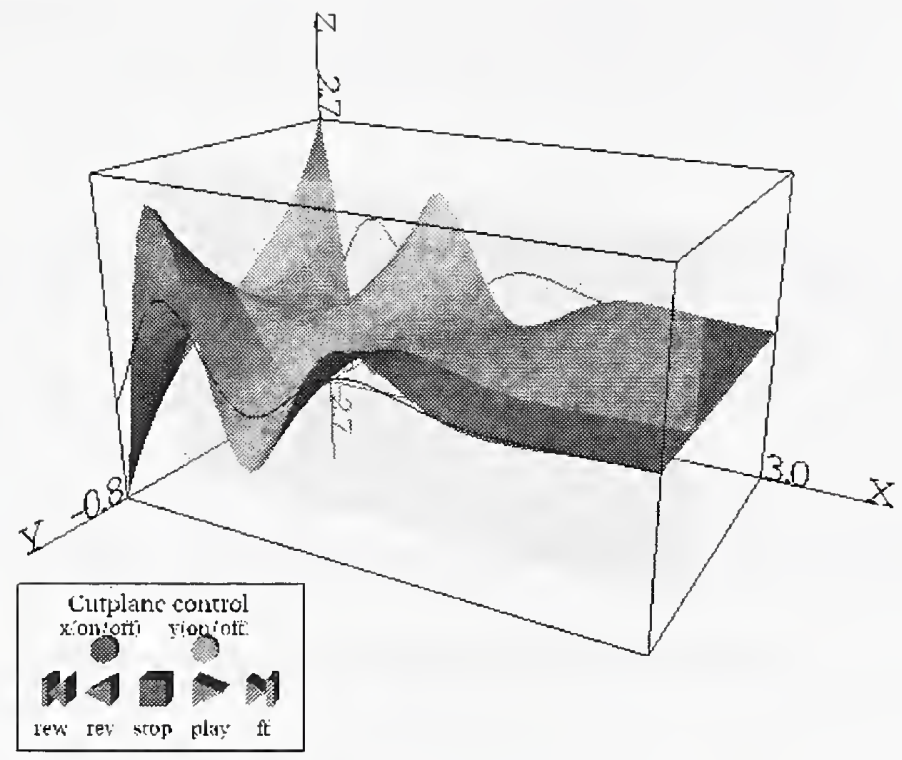

Figure 5: VRML display with Y direction cutting plane.

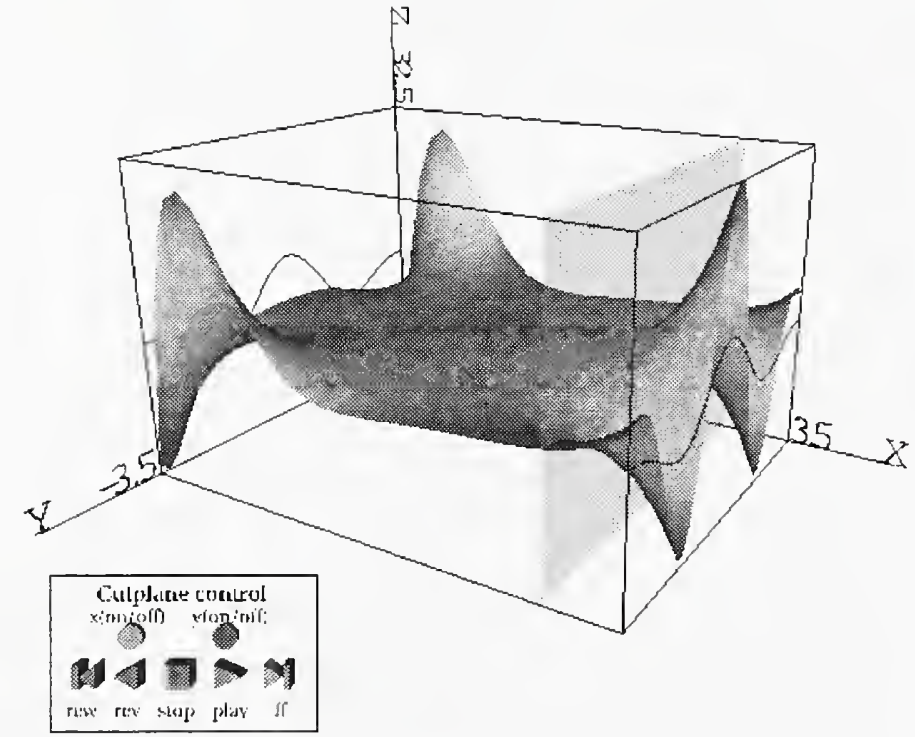

Figure 6: VRML display with $\mathrm{X}$ direction cutting plane. 


\section{Acknowledgements}

We would like to thank Daniel Lozier, Bruce Miller, Frank Olver, Sandy Ressler, Sharon Laskowski, and Marjorie McClain for their very helpful suggestions and support for this work.

\section{References}

[1] M. Abramowitz and I.A. Stegun, editors. Handbook of Mathematical Functions with Formulas, Graphs and Mathematical Tables, Vol. 55, National Bureau of Standards Applied Mathematics Series. U.S. Government Printing Office, Washington, D.C., 1964.

[2] D.W. Lozier, "Toward a Revised NBS Handbook of Mathematical Functions," NISTIR 6072, National Institute of Standards and Technology, September 1997.

[3] D.E. Amos, "A Portable Package for Bessel Functions of a Complex Argument and Nonnegative order," ACM Transactions on Mathematical Software, Vol. 12 (September 1986), pp. 265273.

[4] W.J. Thompson, Atlas for Computing Mathematical Functions, John Wiley and Sons, Inc., New York, 1997, pp. 414-432. 


